\title{
Favorable cardiovascular effects of pioglitazone: a meta-analysis
}

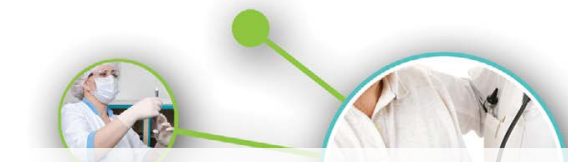

Type 2 diabetes mellitus is caused by insulin resistance and $\beta$ cell failure. Pioglitazone and other thiazolidinediones are the antidiabetic agents that increase insulin sensitivity, reduce blood glucose and hemoglobin A1c levels, inhibit adipose-tissue lipolysis, decrease microalbuminuria, inhibit inflammation, decrease blood pressure and reduce adverse cardiovascular risk. The objective of this review was systematic evaluation of the effect of pioglitazone on mortality and cardiovascular events in the patients with diabetes mellitus.

In the analysis were included randomized, controlled studies after systematic literature search in electronic databases. Risk ratios with $95 \%$ confidence intervals $(\mathrm{Cl})$ were calculated, using the random effect model. Statistical heterogeneity across all the studies was tested with the 12 statistics.

Pioglitazone was associated with statistically significant reduction in non-fatal coronary events (defined as myocardial infarction, unstable angina or coronary revascularization): $\mathrm{RR} 0.62,95 \% \mathrm{Cl}(0.43,0.89)$, but significant heterogeneity was found $(\mathrm{p}=0.00,12=80 \%)$. Mortality rate was not significantly different between pioglitazone users and non-users (RR 0.87 , $95 \% \mathrm{Cl}(0.62,1.23)$. Overall risk for non-fatal heart failure was slightly increased ( $\mathrm{RR} 1.31,95 \% \mathrm{Cl}(1.17,1.47))$. No significant heterogeneity was found for any of these analysis $(12=47 \%, p=0.06$ and $12=10 \%, p=0.35)$.

Pioglitazone is and should remain an important agent within the modern management of type 2 diabetic patients, especially in those at elevated cardiovascular risk.

KEYWORDS: type 2 diabetes, pioglitazone, cardiovascular complications, non-fatal coronary events, mortality, heart failure

\section{Background}

Type 2 diabetes mellitus (T2DM) is characterized by insulin resistance, $\beta$ cell failure, and microvascular and macrovascular complications. There is a two-fold to fourfold increased risk of a macrovascular event in patients with, compared with those without, diabetes [1]. Heart disease was listed as the most frequent and was represented $69.5 \%$ of death cases of people with diabetes [2]. Furthermore, diabetes mellitus predisposes people to premature atherosclerotic coronary artery disease (CAD) another leading cause of mortality [3]. Factors such as diabetes-associated hypertension and dyslipidemia may contribute to the severity of vascular dysfunction in diabetes. Endothelial dysfunction may play a role in the progression of coronary atherosclerosis and these people are at increased risk for cardiac events [4].

Thiazolidinedione drugs (TZDs) are the only current antidiabetic agents that function primarily by increasing insulin sensitivity. Thiazolidinedione's cellular actions are mediated by binding to its nuclear receptor, the peroxisome proliferator-activated receptor gamma (PPAR $\gamma$ ) [5]. PPAR $\gamma$ is expressed at high levels in adipose tissue, where TZDs functions as a master regulator of adipocyte differentiation, and at much lower levels in other tissues [6]. The effects of PPAR $\gamma$ in adipose tissue are proposed to be the main mechanism by which TZD improves insulin sensitivity. Insulin sensitization appears to be the mechanism whereby TZDs prevent or delay development of T2DM in individuals with prediabetes. TZDs lower hemoglobin A1c potently by around $1 \%$ as monotherapy in T2DM, where they notably do not cause hypoglycemia like insulin or insulin secretagogues (i.e., sulfonylureas), and they can be used in combination with other antidiabetic agents [7]. Pioglitazone is one of the TZDs that
Katya Hristova

Uzunova*1,

Elena Pavlova Filipova ${ }^{1}$, Krassimir Boytchev

Kalinov ${ }^{2} \&$

Toni Yonkov Vekov 3

${ }^{1}$ Tchaikapharma High Quality Medicines Inc., Science Department, 1 G.M. Dimitrov Blvd, 1172 Sofia, Bulgaria

${ }^{2}$ New Bulgarian University, Department Informatics, 21 Montevideo Str, 1618 Sofia, Bulgaria

${ }^{3}$ Medical University, Dean of Faculty of Pharmacy, 1 Sv. Kliment Ohriski Str., 5800 Pleven, Bulgaria

*Author for correspondence:

k.uzunova.hq@tchaikapharma.com 
have demonstrated significant benefits on both glycemic control and associated cardiovascular risk factors including hypertension [8] and biochemical markers of risk [9].

In the process of atherogenesis and the subsequent increased cardiovascular mortality of diabetic patients, endothelial dysfunction is suspected to play an important role. There has been increasing evidence that TZDs may have some antiatherogenic actions. It was indicated that pioglitazone in contrast to placebo significantly improves endothelial function as well as insulin resistance in patients with newly diagnosed T2DM and established CAD [10]. PROactive results showed that pioglitazone reduces incident vascular events in type 2 diabetic patients with manifested atherosclerosis [11].

Measurement of carotid intima-media thickness (IMT) has been validated as a measure of atherosclerosis and as a strong predictor of cardiovascular events (myocardial infarction and stroke). Many human studies noted a reduction in IMT after 12 or 24 weeks of treatment with pioglitazone $[12,13]$ and trough PPAR $\gamma$ activation pioglitazone caused an inhibition of early atherosclerotic process. Data suggested that pioglitazone and other thiazolidinediones decrease C-reactive protein levels [9], microalbuminuria [14], arterial pulse-wave velocity [9], systolic and diastolic blood pressure [8], and increase adiponectin levels [9], each of which is associated with cardiovascular risk reduction. Moreover, PPAR $\gamma$ activation leads to a reduction in blood concentrations of matrix metalloproteinase-9 [15] and soluble CD40 ligand [16], both new markers of cardiovascular risk.

The therapeutic use of pioglitazone has been limited in recent years due to concerns over bladder carcinogenicity, the description of new risk for fractures and due to increased risk of cardiovascular harm with rosiglitazone [17]. Meta-analyses showed increased risk for myocardial infarction associated with rosiglitazone $[18,19]$. Different effects of rosiglitazone and pioglitazone on cardiovascular complications suggests that these effects are rather associated with the TZD type. Subgroup analyses of randomized clinical trial PROactive show that pioglitazone is effective in reducing the risk of recurrent stroke: HR 0.53 (95\% CI 0.340.85, $\mathrm{p}=0.009)$ [20] and recurrent myocardial infarction (MI) and other serious cardiovascular event in patients with T2DM and previous MI: HR 0.72 (95\% CI $0.52-0.99, \mathrm{p}=0.045)$ [21], although $6 \%$ from the group on pioglitazone have been admitted to hospital with heart failure [11].
In the present meta-analysis we want to demonstrate that pioglitazone is a valuable option for diabetic patients with potential cardiovascular benefits. The objective of the meta-analysis was to systematically assess the effect of pioglitazone on mortality and the incidence of cardiovascular complications, using data from the randomized controlled trials of pioglitazone in diabetes mellitus.

\section{Methods}

\section{- Study selection}

Published papers and abstracts were identified by a literature search of electronic databases that include: PubMed (www.ncbi. nlm.nih.gov/pubmed), Medline, Scopus (www. scopus.com), PsyInfo, Russian scientific library (eLIBRARY.ru), sources for unpublished trials are the clinical trials registers, such as www. clinicaltrials.gov, www.clinicaltrialsregister.eu. Additionally, unpublished materials and results of clinical trials were sought through informal channels and personal communication with researchers who have been working in the relevant field. We searched for articles published in English and Russian languages from 2000 to February 2016. The pre-specified inclusion criteria used for assessment of studies were: 1 . Type of study: epidemiological, controlled and blind, randomized; 2. Type of participants: representative group from whole population, specific strata; 3 . Access to the primary source data; 4. Eligibility of statistical analysis. Eligible studies were hard to find because they weren't fully available or weren't published at all (publication bias). This meta-analysis is designed to cover all the relevant published and unpublished materials. FIGURE 1 presents a flow-diagram which describes the process of screening of identified studies.

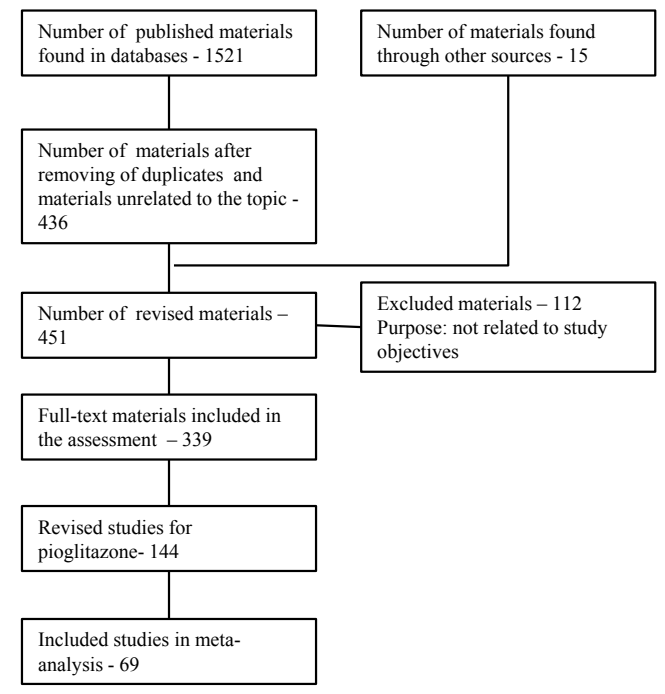

FIGURE 1. Diagram of the process of source screening. 


\section{- Outcome measures}

The included various studies, which observed the effects of pioglitazone on the cardiovascular events, measure different outcomes and very different time intervals. We specified the primary outcomes of this meta-analysis:

- Mortality (total and related to cardiovascular events)

- Non-fatal coronary events (defined as myocardial infarction, unstable angina or coronary revascularization)

- Non-fatal heart failure requiring hospitalization.

All studies (TABLE 1), included in the analysis, were randomized, controlled clinical studies. For each study, numbers of patients with events of interest were extracted for each treatment group and used to calculate relative risks. We estimated overall relative risks (RR) and $95 \%$ confidence intervals (CIs) for each end points using random effect model.

\section{- Statistical analysis}

Because statistical heterogeneity was present in the results of studies, therefore, the randomeffects model was used. In the random-effects model, studies are weighted with the inverse of their variance and the heterogeneity parameter.

Forest plots were constructed based on random-effects models, and between-study heterogeneity was assessed by graphical inspection and with the Higgins I2 statistic, which describes the percentage of betweenstudy variability in effect estimates attributable to true heterogeneity rather than chance. The Cochran's $Q$ statistic, a chi-squared $(\chi 2)$ test of heterogeneity and Tau 2 , estimating the betweenstudy variance, are also presented. The used level of significance was 0.05 and confidence intervals were respectively $95 \%$.

\section{- Publication bias}

We used funnel and Doi plots to evaluate reports for publication bias. In the meta-analysis, the $\log$ of the ratio measure and its standard error are used in funnel plots. A Doi plot (a symmetrical mountain-like plot) with Luis Furuya-Kanamori (LFK) index $<|1|$ indicates no asymmetry; LFK index between $|1|$ and $|2|$ suggests minor asymmetry; and LFK index $>|2|$ suggests major asymmetry.

Meta-analysis was performed with $\mathrm{R}$ language and Excel macro MetaXL.

\section{Results}

\section{- Mortality}

Compared to all studies with cardiovascular end-points (FIGURE 2) only the PROactive study and one unpublished study, due to the small number of participants, reported for death patients.

The PROactive (Prospective Pioglitazone Clinical Trial in Macrovascular Events) study reported that the total mortality in the group of pioglitazone was 177 compared with 186 deaths in the placebo group and suggested that the use of pioglitazone did not influence the total mortality. In other studies, different from PROactive, the results were more definitive: in the group of patients with type 2 diabetes participating in these studies, the total number of reported deaths was 17 and in the group of non-users of pioglitazone were 39. From the calculated RR $0.41,95 \%$ CI $(0.23$ to 0.72$)$ (FIGURE 2) could be concluded that the use of pioglitazone was associated with a significantly reduced risk of mortality.

When long-term studies were analyzed separately from short-term, a lower risk of total mortality with the use of pioglitazone were found in both cases, although the number of short-term studies was small and therefore couldn't achieve statistical significance.

In the comparative analysis of pioglitazone with other antidiabetic agents, pioglitazone showed lower mortality rates than the groups treated with sulfonylureas (RR $0.22 \quad 95 \%$ CI (0.05 to 1.03$)$ ), placebo (RR $0.1695 \% \mathrm{CI}$ (0.02 to 1.45)), metformin (RR $0.6695 \% \mathrm{CI}$ (0.19 to 2.34)), rosiglitazone (RR $0.49 \quad 95 \%$ CI (0.04 to 5.36)), glitazars (RR $0.42 \quad 95 \%$ CI (0.11 to 1.61)) but the overall result did not reached statistical significance (FIGURE 2). When studies with zero mortality were included in the analysis, there was no statistically significant difference in RR in all groups.

Information on causes of death was missing in five of the studies. In other studies participated 7644 patients, who were pioglitazone users and in this group were reported 7 deaths due to cardiovascular events. However, in the comparative group with 6106 patients were reported 16 deaths due to cardiovascular events (RR $0.35,95 \%$ CI (0.14 to 0.85$)$ ). The overall random effect relative risk was RR $0.87,95 \% \mathrm{CI}$ (0.62 to 1.23 ), but with substantial heterogeneity (I2=47\%) (FIGURE 2). The funnel and Doi plot in FIGURE 3 were asymmetrical with LFK index $>|2|$, suggesting gross publication bias.

- Non-fatal coronary events (defined as myocardial infarction, unstable angina or coronary revascularization)

PROactive study suggested that pioglitazone significantly decrease the number of case with 


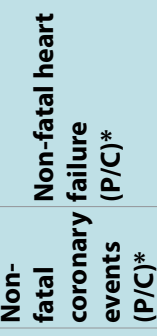

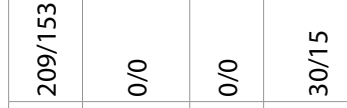

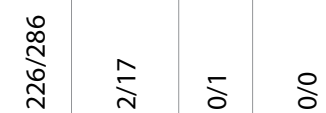

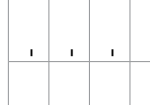

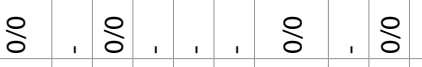

옹

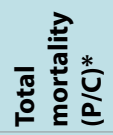

$\stackrel{\infty}{\aleph}$

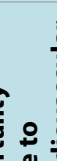

高

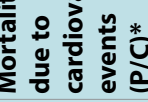

¿

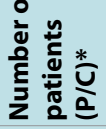

$\stackrel{\substack{n \\ N}}{N}$

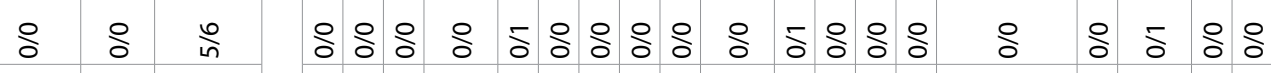

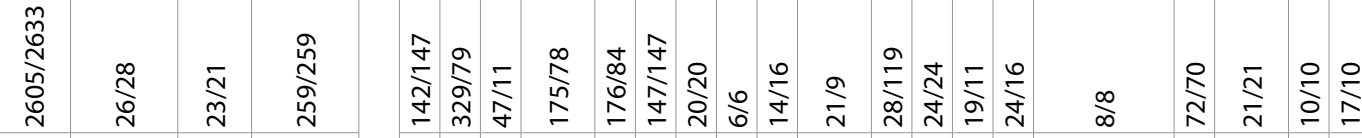

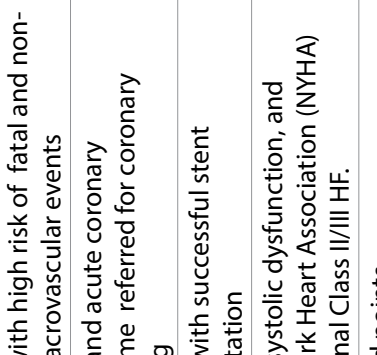

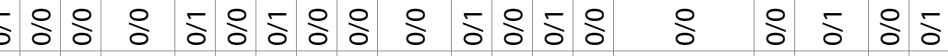

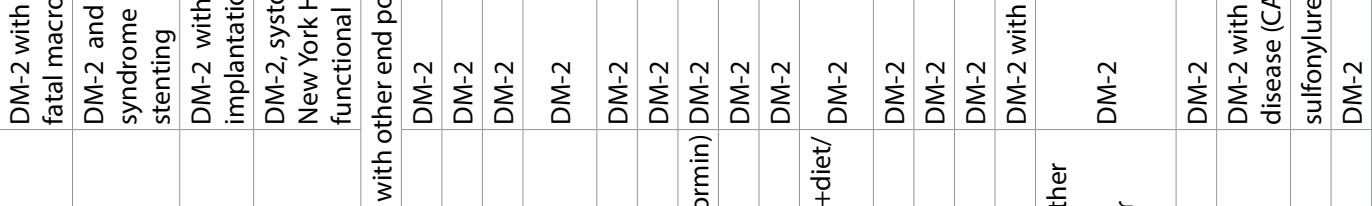

I

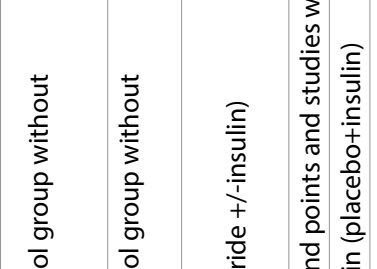

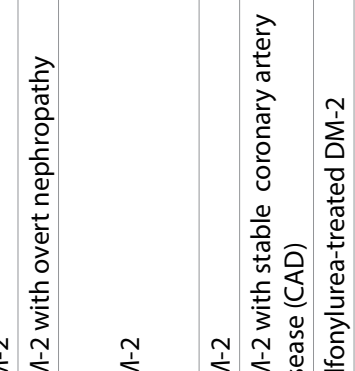
$\frac{6}{\frac{6}{2}} \div \frac{0}{2} \div \frac{\circ}{2} \div$

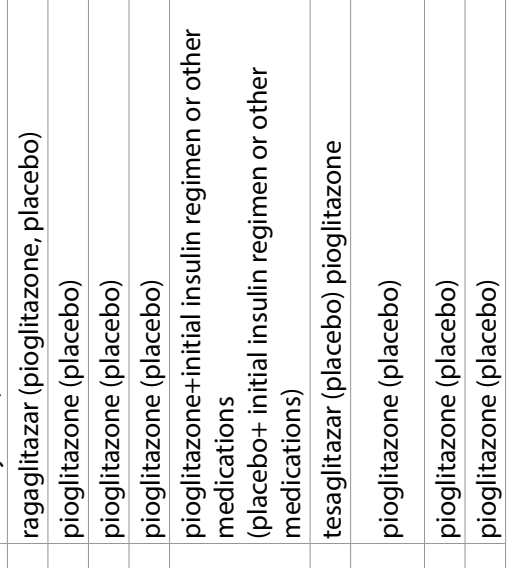

\begin{tabular}{|c|c|c|c|c|c|c|c|c|c|c|c|c|c|c|c|c|c|c|c|}
\hline 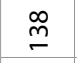 & $\stackrel{\Delta}{\sim}$ & $\stackrel{ \pm}{\sim}$ & $\stackrel{d}{\sim}$ & 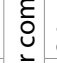 & 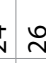 & $\stackrel{2}{\sim}$ & $\stackrel{\gtrless}{\sim}$ & $\stackrel{d}{\sim}$ & $\stackrel{i}{\sim} \infty$ & $\infty \circ$ & 0 & $\simeq$ & $\simeq$ & $\simeq \simeq$ & $\simeq$ & $\simeq$ & $\simeq$ & $\simeq$ & \\
\hline 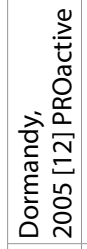 & 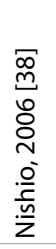 & 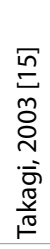 & 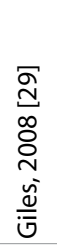 & 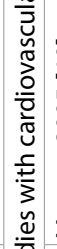 & 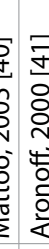 & 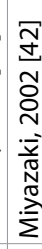 & 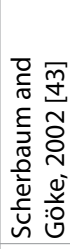 & 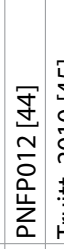 & 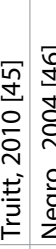 & 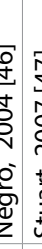 & 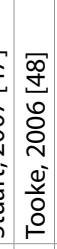 & 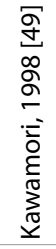 & 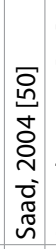 & 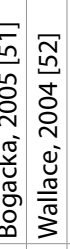 & 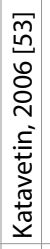 & 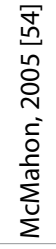 & 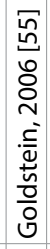 & 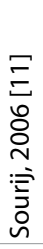 & 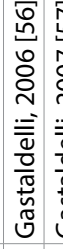 \\
\hline & 0 & $m$ & & & & & $\infty$ & $a$ & $\stackrel{=}{=}$ & $E ?$ & $\underline{m}$ & $\Xi$ & $\stackrel{\sim}{\sim}$ & $6=$ & $\stackrel{\infty}{\sim}$ & $\stackrel{9}{-}$ & i & $\bar{N}$ & \\
\hline
\end{tabular}




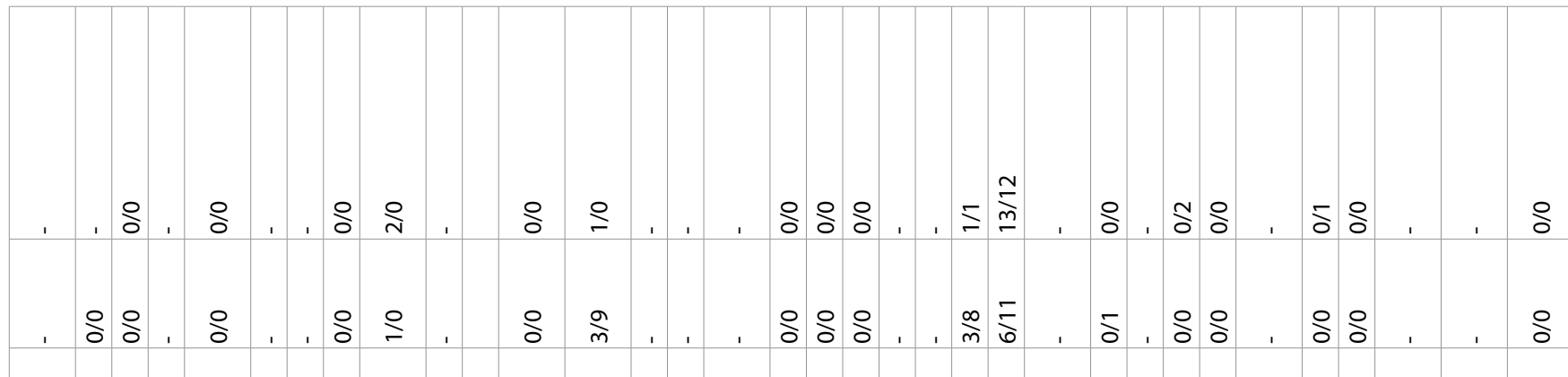

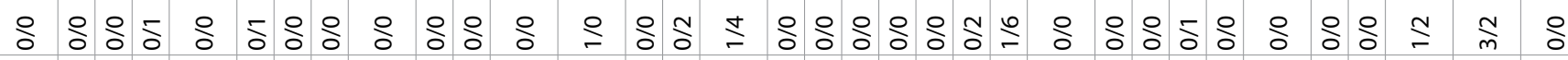

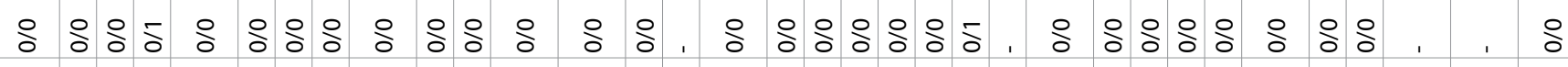

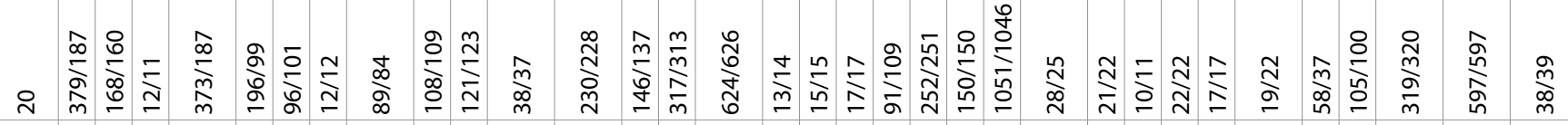

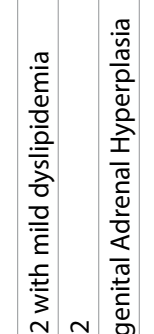

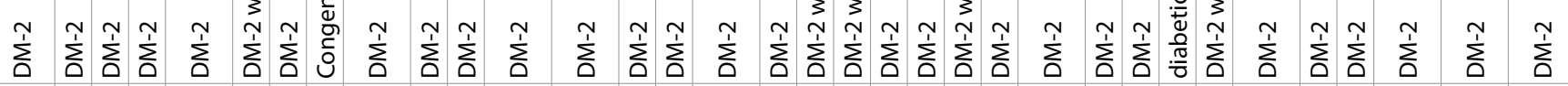
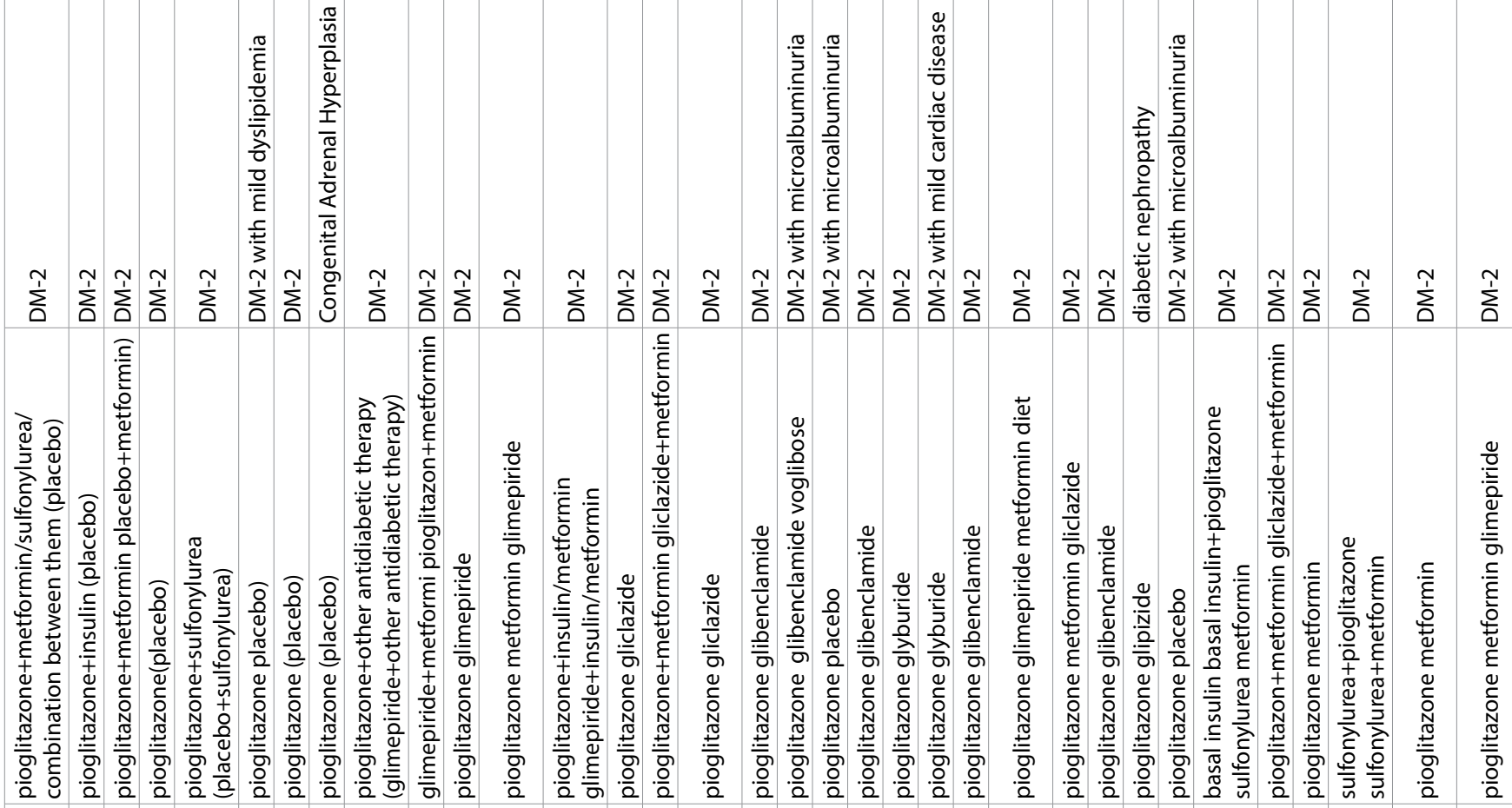

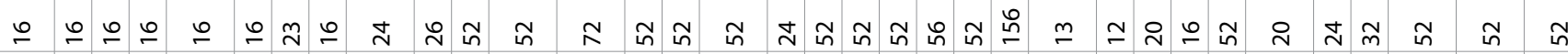

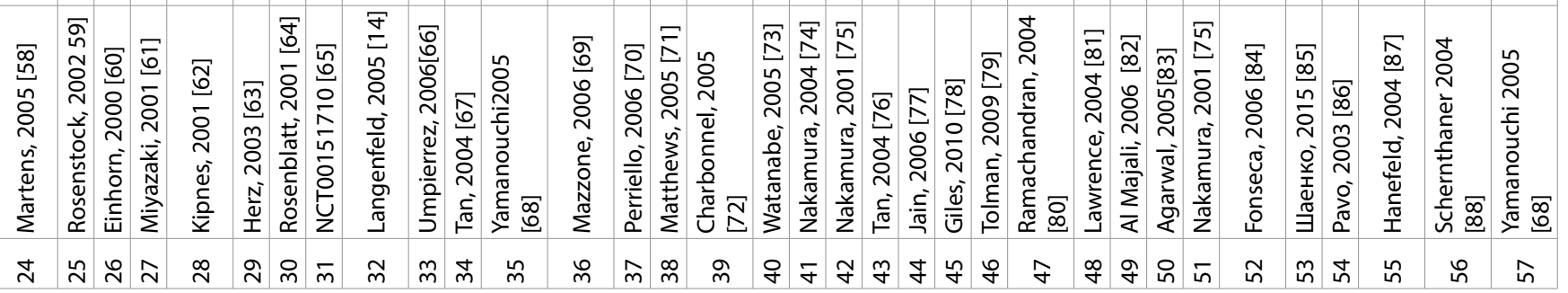




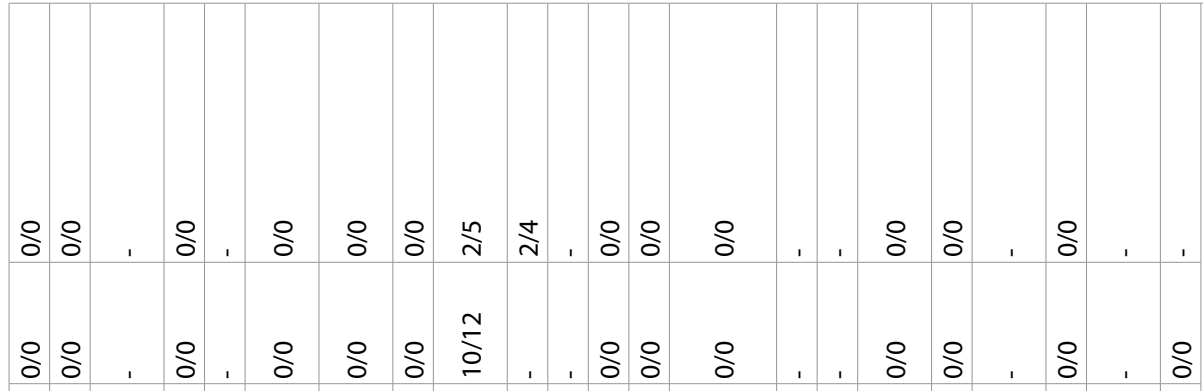

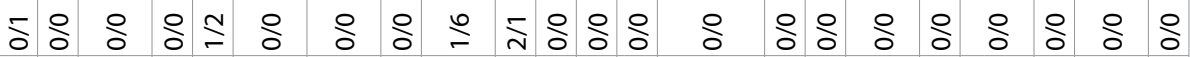

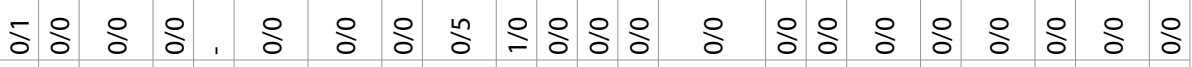

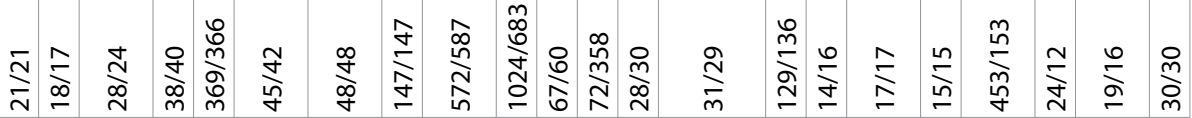

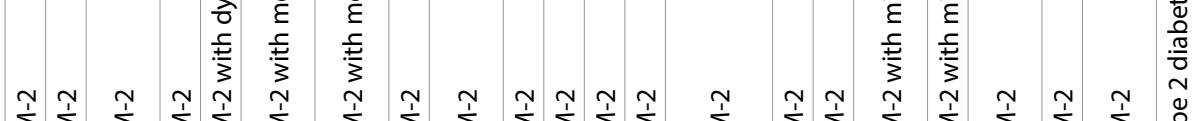
$\sum_{0}^{N} \sum_{0}^{N} \sum_{0}^{N} \sum_{0}^{N} \sum_{0}^{N} \sum_{0}^{N} \sum_{0}^{N} \sum_{0}^{N} \sum_{0}^{N} \sum_{0}^{N} \sum_{0}^{N} \sum_{0}^{N} \sum_{0}^{N} \sum_{0}^{N} \sum_{0}^{N} \sum_{0}^{N} \sum_{0}^{N} \sum_{0}^{N} \sum_{0}^{N} \sum_{0}^{N} \sum_{0}^{N} \frac{D}{N}$

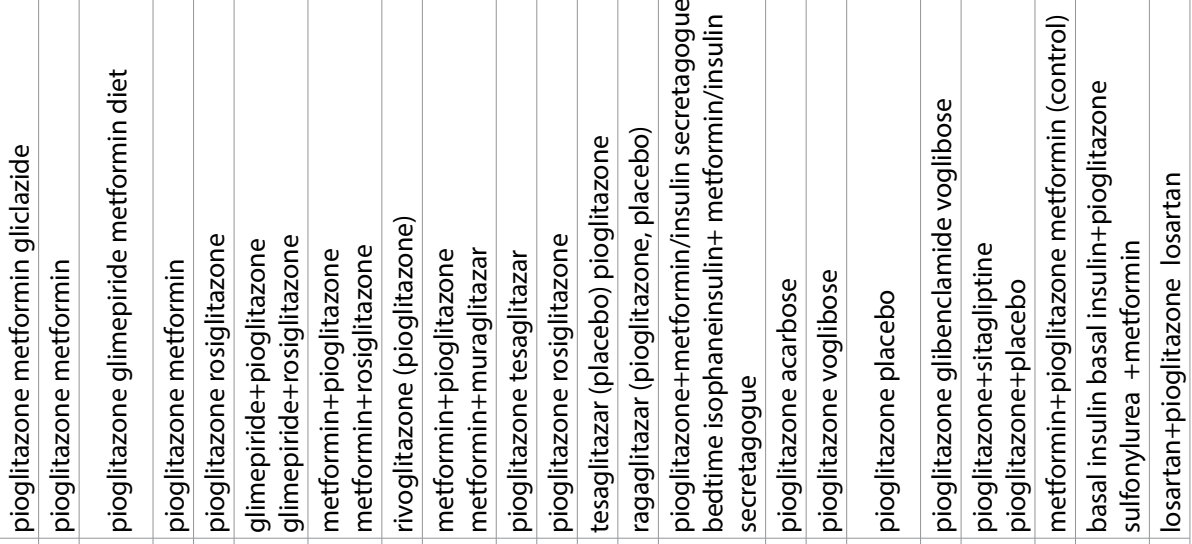

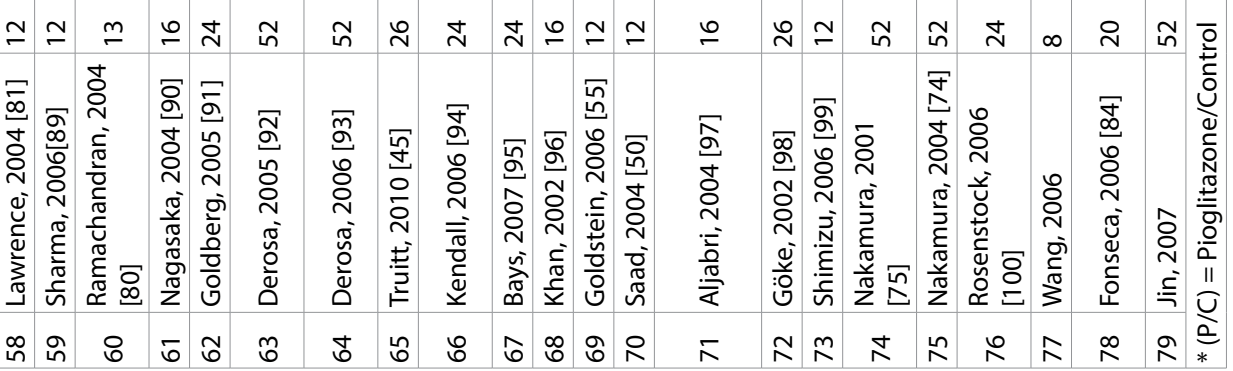




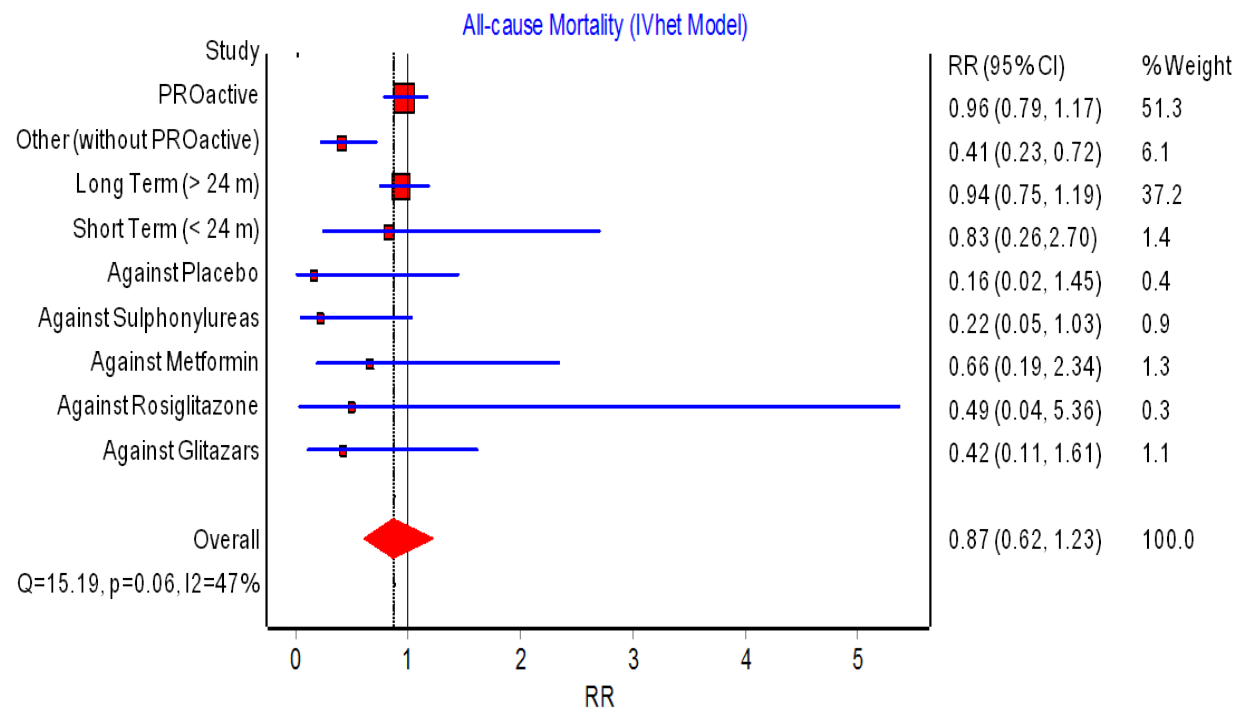

FIGURE 2. Forest plot - all-cause mortality.
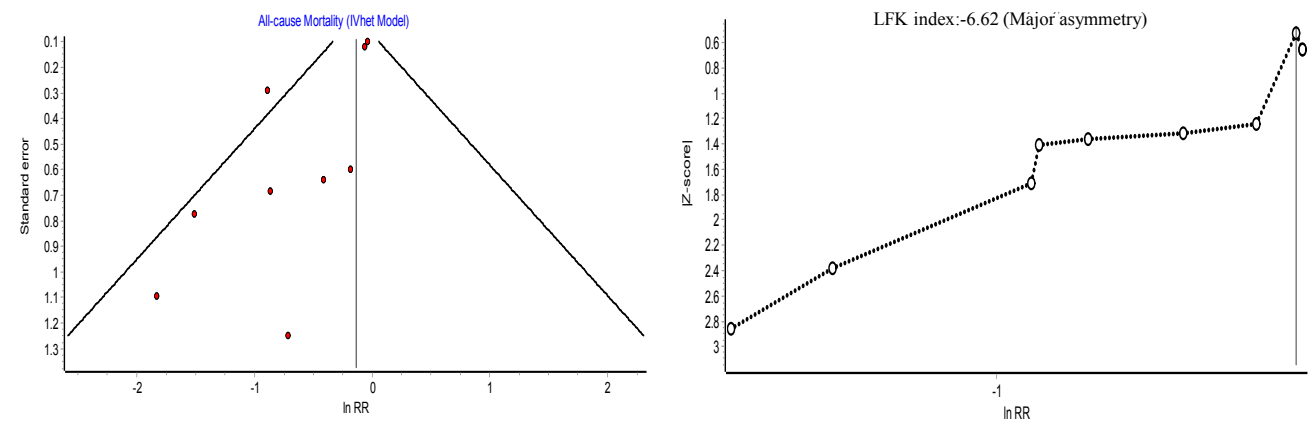

FIGURE 3. Detection of publication bias: funnel plot (left) and Doi plot (right) - all-cause mortality.

non-fatal coronary events (FIGURE 4). In the cohort of diabetic patients, information about non-fatal coronary events was reported in 40 studies involving 4259 patients on pioglitazone and 3989 patients as controls. These studies reported respectively 44 and 50 non-fatal coronary events and calculated risk ratio was RR $0.64,95 \%$ CI $(0.44,0.92)$. The same data transformed as the incidence rate per 1000 year disclosed that there will be 8.8 cases of non-fatal coronary events per 1000 years in the group of users of pioglitazone and 10.2 cases of non-fatal coronary events per 1000 years in the group of controls. If all of the studies were analyzed, including PROactive, the calculated relative ratio (RR 0.62, 95\% CI $(0.43,0.89))$ revealed that the use of pioglitazone is associated with significant reduction in risk of non-fatal coronary events but the effect estimates were heterogeneous across the studies, I2=80\% (FIGURE 4). There was evidence of minor asymmetry in the Doi plot (LFK <|2|) (FIGURE 5).

\section{Non-fatal heart failure requiring} hospitalization

In PROactive study the use of pioglitazone is associated with increased risk of non-fatal cases of heart failure (FIGURE 6). Other studies that have reported non-fatal heart failure requiring hospitalization included 5380 patients using pioglitazone and 5531 controls. The number of cases with heart failure was 58 for the pioglitazone group and 39 for the control group. Accordingly, the calculated relative risk was RR $1.32,95 \%$ CI $(0.88,1.18)$. Increased risk of heart failure was shown when comparing pioglitazone and placebo (RR 1.30, 95\% CI $(1.06,1.59))$ but such increased risk was not established when comparing pioglitazone with glitazars and sulphonylureas (RR $0.43,95 \% \mathrm{CI}$ $(1.13,1.39)$ and RR $0.96,95 \%$ CI $(0.48,1.89)$, respectively). There was moderate heterogeneity across the studies for this end point (I2 $=10 \%$, $\mathrm{p}=0.35$ ).

Combination of all studies reported at least one case of non-fatal heart failure, without PROactive, showed statistically non-significant 
difference between group of pioglitazone and non-fatal heart failure (FIGURE 6). Asymmetry controls. The inclusion of PROactive study in of funnel and Doi plots showed evidence of the analysis significantly increased the risk of publication bias (FIGURE 7).

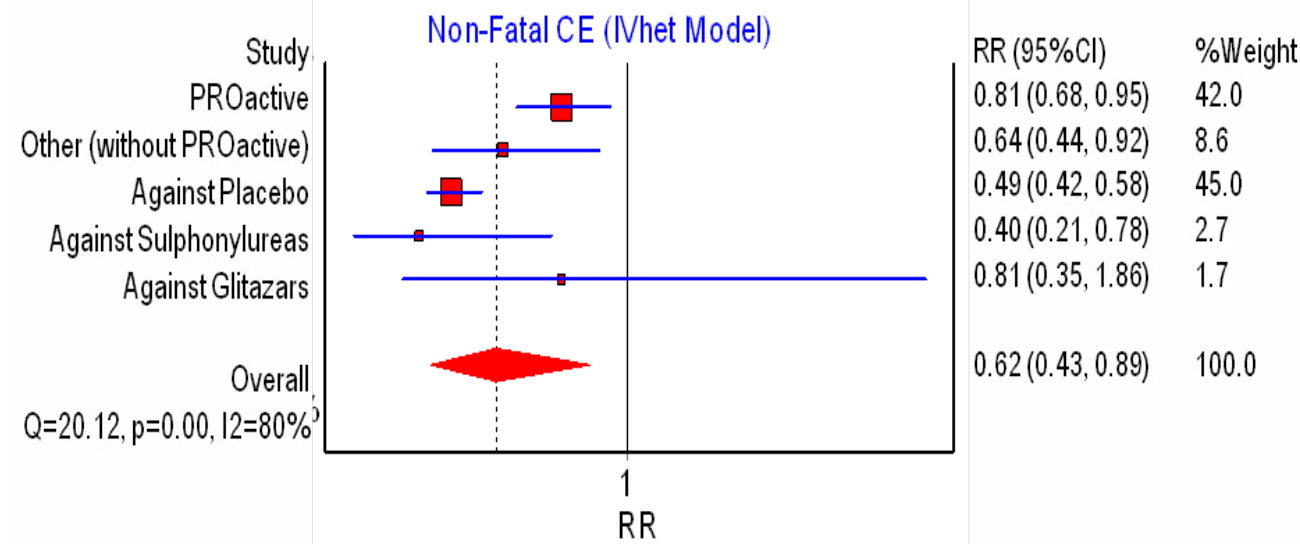

FIGURE 4. Forest plot - non-fatal coronary events
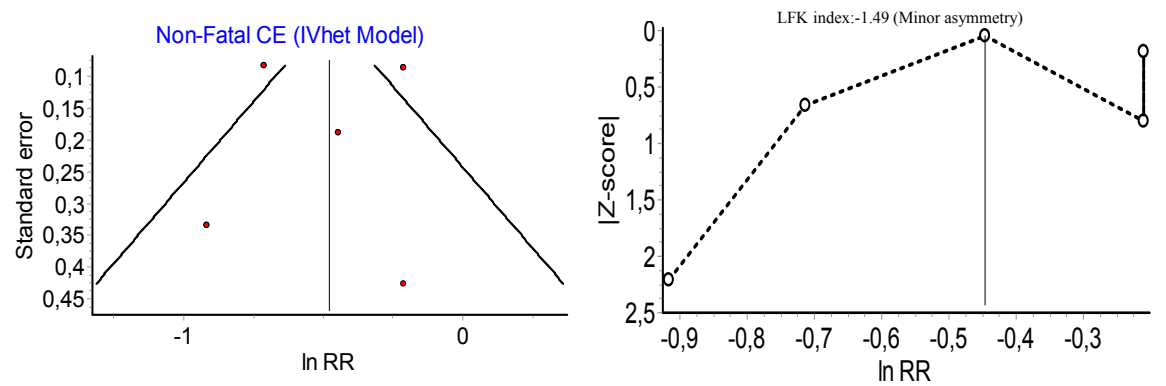

FIGURE 5. Detection of publication bias: funnel plot (left) and Doi plot (right) - non-fatal coronary events.

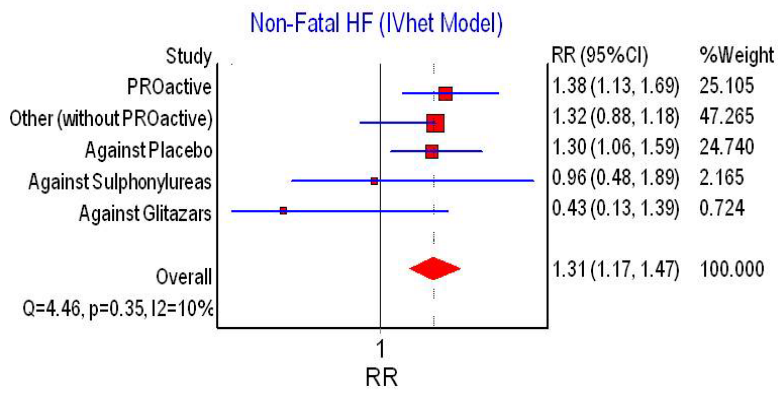

FIGURE 6. Forest plot - non-fatal heart failure.
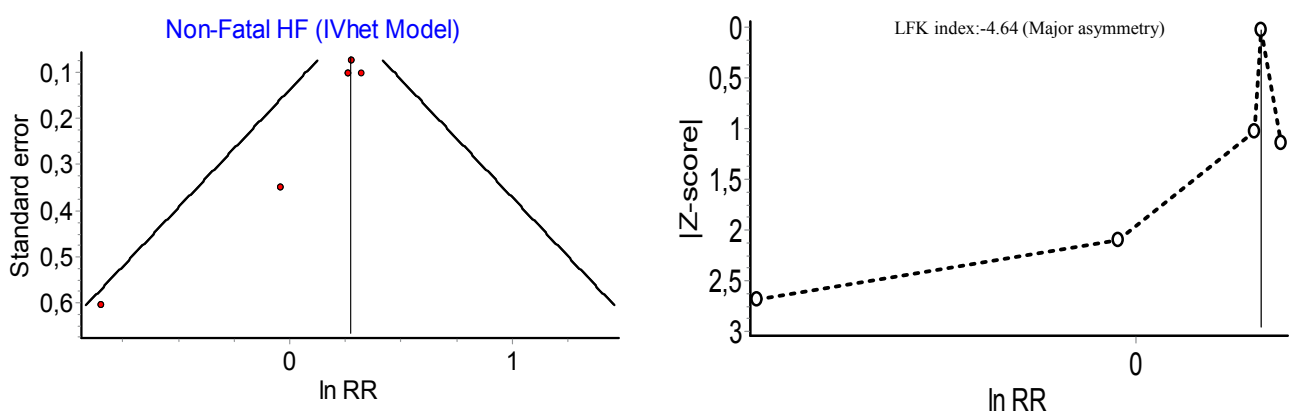

FIGURE 7. Detection of publication bias: funnel plot (left) and Doi plot (right) - non-fatal heart failure. 


\section{Discussion}

Our data support the expectation for reduced risk (around 60\%) of total mortality in the group of pioglitazone (without PROactive study). In the comparative analysis of total mortality between users of pioglitazone and users of other antidiabetic agents, a similar conclusion was made: risk of death in the group of pioglitazone was lower than in groups of sulphonylureas (78\%), metformin $(34 \%)$, rosiglitazone $(51 \%)$, glitazars (58\%) and in the placebo group (84\%), but the overall result did not reached statistical significance. The risk of non-fatal coronary events was decreased between $16 \%$ and $60 \%$ in the group of pioglitazone. The PROactive study found that despite the increased cases of heart failure in the pioglitazone group, the number of deaths from heart failure was similar in each group. Our findings showed that there was an association (under 50\%) between pioglitazone and risk of heart failure.

Pioglitazone seem to have more favorable effect on cardiovascular disease. Pioglitazone and metformin are the only glucose- lowering agents with RCT data demonstrating a reduction in stroke, MI and death in type 2 diabetes [22]. A large clinical trial designed to assess the effect of pioglitazone on ischemic cardiovascular outcomes, the Prospective Pioglitazone Clinical Trial in Macrovascular Events (PROactive) trial, proved that pioglitazone significantly reduced the secondary composite outcome of allcause mortality, non-fatal MI and stroke (HR $0.84,95 \%$ CI $0.72-0.98$ ) but indicated $11 \%$ increased chances of congestive heart failure in pioglitazone-treated patients [11].

A meta-analysis of 19 trials also showed the benefit of pioglitazone in regard to cardiovascular events, with an $18 \%$ reduced risk of the composite end point of all cause death, MI and stroke [23]. Another metaanalysis, comprising randomized controlled trials, suggested that pioglitazone did not appear to increase the risk of MI (RR 0.86, 95\% CI $(0.69,1.07), \mathrm{p}=0.17)$ and the authors didn't find statistically significant reduction in stroke and coronary revascularisation compared to control [24]. While one meta-analysis of clinical trials found a trend toward elevated risks of myocardial infarction and death from cardiovascular causes with rosiglitazone [18] other meta-analysis of randomized clinical trials stated that there was an increased risk of heart failure compared with control for both rosiglitazone (RR 2.18, 95\% CI $(1.44,3.32), \mathrm{p}=0.0003$; 5 studies $)$ and pioglitazone (RR $1.32,95 \%$ CI $(1.04,1.68)$, $\mathrm{p}=0.02 ; 2$ studies), but the risk of cardiovascular death was not significantly increased for TZD compared with control, nor for rosiglitazone and pioglitazone compared with control [25].
According to Fishman and Tenenbaum the risk of heart failure is a class effect of TZDs, whereas the ischemic cardiovascular risk is restricted to rosiglitazone but not to pioglitazone [26].

Observational studies suggest no increased ischemic heart disease (IHD) risk with pioglitazone compared with other oral hypoglycemic agents [27]. A Taiwan retrospective cohort study of over 473000 patients showed that rosiglitazone monotherapy were at higher risk for any cardiovascular event (hazard ratio [HR] 1.89, 95\% CI 1.57, 2.28), myocardial infarction (HR 2.09, 95\% CI 1.36, 3.24), angina pectoris (HR 1.79, 95\% CI $1.39,2.30)$ and transient ischaemic attack (HR $2.57,95 \%$ CI 1.33 , 4.96) than those receiving metformin monotherapy, but pioglitazone as an add-on therapy was found to have a favourable, but nonsignificant, effect on outcome [28]. The WellPoint observational study revealed that there was no significant increase in risk of MI (HR 1.04, 95\% CI 0.91 - 1.21) [29]. Using population-based health care databases in Ontario were found that TZD treatment was associated with a significant increase in the risks of congestive heart failure (CHF), acute myocardial infarction, and all-cause mortality among older persons but this association was significant only with rosiglitazone therapy [30]. One observational study documented that TZDs and metformin were not associated with increased mortality and may improve outcomes in older patients with diabetes and heart failure [31]. Moreover, only pioglitazone has been shown to reduce the incidence of major cardiovascular events $[11,23]$.

As a class, TZDs turn on and off many of the same genes. The function of the target genes have been mainly concentrated on hepatocytes and adipocytes, which both play a key role in systemic lipid metabolism [32]. However, each PPAR $\gamma$ agonist has its own individual effect to stimulate/inhibit the expression of specific genes. This is particularly relevant to pioglitazone and rosiglitazone, which have very different effects on lipid metabolism. Pioglitazone compared with rosiglitazone is associated with significant improvements in triglycerides, HDL cholesterol, LDL particle concentration, and LDL particle size [33], which may be associated with their different effect on cardiovascular outcomes. Moreover, thiazolidinediones exert antiatherogenic effects through a multitude of mechanisms, including a decrease in insulin resistance, inhibition of atherogenic processes in the vascular wall, and a reduction in established and new cardiovascular risk factors. Furthermore, pioglitazone treatment improves chronic vascular inflammation (decrease of 
biomarker hsCRP), which may be associated with reduced cardiovascular risk [34].

\section{Conclusions}

In summary, T2DM as a chronic metabolic disorder is associated with a marked increase in cardiovascular disease, morbidity and mortality, but the majority of published studies do not suggest such an increased risk in pioglitazonetreated patients. Our work shows that pioglitazone treatment was associated with non-significant decrease in mortality rate and reduction of non-fatal cardiovascular events (defined as myocardial infarction, unstable angina or coronary revascularization) but a slight risk of non-fatal heart failure was found.

Although pioglitazone may also be associated with several adverse events, including body weight gain, $\mathrm{CHF}$, peripheral bone fractures, the value of pioglitazone as a glucoselowering agent (as oral monotherapy, dual therapy, triple therapy and even combination with insulin) were confirmed, with additive positive effects that may contribute to coronary and cerebrovascular protection.

The goal of diabetes therapy is not only glucose lowering, but also protection from its comorbidities. In this aspect, pioglitazone is and should remain an important agent within the modern management of type 2 diabetic patients, and its clinical use should be consistent with the individual patient's characteristics since pioglitazone exerts cardioprotective action and has proven to be cost-effective [35-37] in patients with T2DM and macrovascular disease [39].

\section{Financial and competing interests}

\section{disclosure}

Tchaikapharma High Quality Medicines Inc. funded this meta-analysis. KHU and EPF are employees of Tchaikapharma High Quality Medicines Inc. The other authors report no competing interests.

\section{Authors' contributions}

The original idea came from TYV. KBK assessed the eligibility of the studies and performed statistical analysis. KHU checked all the selected articles for this review and wrote the article. EPF independently checked data and contributed in writing the manuscript. All authors revised and provided final approval of this manuscript. 


\section{REFERENCES}

Stamler J, Vaccaro O, Neaton JD, Wentworth D. Diabetes, other risk factors, and 12-yr cardiovascular mortality for men screened in the Multiple Risk Factor Intervention Trial. Diabetes Care. 16(2), 434-444 (1993).

Gu K, Cowie CC, Harris MI. Mortality in adults with and without diabetes in a national cohort of the U.S. population, 1971-1993. Diabetes Care. 21, 1138-1145 (1998).

Gu K, Cowie CC, Harris MI. Diabetes and decline in heart disease mortality in U.S. adults. JAMA. 281, 1291-1297 (1999).

Suwaidi JA, Hamasaki S, Higano ST, et al. Long-term follow-up of patients with mild coronary artery disease and endothelial dysfunction. Circulation. 101(9), 948-954 (2000).

Lehmann JM, Moore LB, SmithOliver TA, et al. An antidiabetic thiazolidinedione is a high affinity ligand for peroxisome proliferator-activated receptor gamma (PPAR gamma). J. Biol. Chem. 270, 12953-12956 (1995).

Tontonoz P, Spiegelman BM. Fat and beyond: the diverse biology of PPARgamma. Annu. Rev. Biochem. 77, 289-312 (2008).

Soccio RE, Chen ER, Lazar MA. Thiazolidinediones and the Promise of Insulin Sensitization in Type 2 Diabetes. Cell Metab. 20(4), 573-591 (2014).

Gerber P, Lubben G, Heusler S, Dodo A. Effects of pioglitazone on metabolic control and blood pressure: a randomised study in patients with type 2 diabetes mellitus. Curr. Med. Res. Opin. 19, 532539 (2003).

Satoh N, Ogawa Y, Usui T, et al. Antiatherogenic effect of pioglitazone in type 2 diabetic patients irrespective of the responsiveness to its antidiabetic effect. Diabetes Care. 26(9), 2493-2499 (2003).

Sourij H, Zweiker R, Wascher TC. Effects of pioglitazone on endothelial function, insulin sensitivity, and glucose control in subjects with coronary artery disease and new-onset type 2 diabetes. Diabetes Care. 29, 1039-1045 (2006).

Dormandy JA, Charbonnel B, Eckland DJ, et al. Secondary prevention of macrovascular events in patients with type 2 diabetes in the PROactive Study (PROspective pioglitAzone Clinical Trial In macroVascular Events): a randomised controlled trial. Lancet. 366(9493), 12791289 (2005).

Yanagawa T, Araki A, Sasamoto K, Shirabe S, Yamanouchi T. Rapid communication: inhibitory effect of pioglitazone on carotid arterial wall thickness in type 2 diabetes. J. Clin. Endocrinol. Metab. 86(7), 3452-3456 (2001).

Langenfeld MR, Forst T, Hohberg C, et al. Pioglitazone decreases carotid intima-media thickness independently of glycemic control in patients with type 2 diabetes mellitus: results from a controlled randomized study. Circulation. 111(19), 2525-2531 (2005).

Yanagawa T1, Araki A, Sasamoto $K$, Shirabe S, Yamanouchi T. Effect of antidiabetic medications on microalbuminuria in patients with type 2 diabetes. Metabolism. 53(3), 353-357 (2004).

Marx N, Froehlich J, Siam L, et al. Antidiabetic PPAR gamma-activator rosiglitazone reduces MMP-9 serum levels in type 2 diabetic patients with coronary artery disease. Arterioscler. Thromb. Vasc. Biol. 23(2), 283-288 (2003).

Varo N, Vicent D, Libby P, et al. Elevated plasma levels of the atherogenic mediator soluble CD40 ligand in diabetic patients: a novel target of thiazolidinediones. Circulation. 107(21), 2664-2669 (2003).

Graham DJ, Ouellet-Hellstrom R, MaCurdy TE, et al. Risk of acute myocardial infarction, stroke, heart failure, and death in elderly Medicare patients treated with rosiglitazone or pioglitazone. JAMA. 304(4), 411-418 (2010).

Nissen SE, Wolski K. Effect of rosiglitazone on the risk of myocardial infarction and death from cardiovascular causes. N. Engl. J. Med. 356, 2457-2471 (2007).

Nissen SE, Wolski K. Rosiglitazone revisited: an updated metaanalysis of risk for myocardial infarction and cardiovascular mortality. Arch. Intern. Med. 170(14), 1191-1201 (2010).

Wilcox R, Bousser MG, Betteridge DJ, et al. Effects of pioglitazone in patients with type 2 diabetes with or without previous stroke: results from PROactive (PROspective pioglitAzone Clinical Trial In macroVascular Events 04). Stroke. 38(3), 865-873 (2007).

Erdmann E, Dormandy JA, Charbonnel B, et al. The effect of pioglitazone on recurrent myocardial infarction in 2,445 patients with type 2 diabetes and previous myocardial infarction. Results from the PROactive (PROactive 05) Study. J. Am. Coll. Cardiol. 49(17), 1772-1780 (2007).

Ryder REJ. Pioglitazone: an agent which reduces stroke, myocardial infarction and death and is also a key component of the modern paradigm for the optimum management of type 2 diabetes. Br. J. Diabetes Vasc. Dis. 11, 113120 (2011).

Lincoff AM, Wolski K, Nicholls SJ, Nissen SE. Pioglitazone and risk of cardiovascular events in patients with type 2 diabetes mellitus: A meta-analysis of randomized trials. JAMA. 298(10), 11801188 (2007).

Nagajothi N, Adigopula $S$, Balamuthusamy $S$, et al. Pioglitazone and the risk of myocardial infarction and other major adverse cardiac events: a meta-analysis of randomized, controlled trials. Am. J. Therapeutics. 15(6), 506-511 (2008).

Lago RM, Singh PP, Nesto RW. Congestive heart failure and cardiovascular death in patients with prediabetes and type 2 diabetes given thiazolidinediones: a meta-analysis of randomised clinical trials. Lancet. 370(9593), 1129-1136 (2007).

Fishman EZ, Tenenbaum A. A cardiologic approach to non-insulin antidiabetic pharmacotherapy in patients with heart disease. Cardiovasc. Diabetol. 8 , 38 (2009).

Kaul S, Bolger AF, Herrington D, Giugliano RP, Eckel RH. Thiazolidinedione Drugs and Cardiovascular Risks. J. Am. Coll. Cardiol. 55(17), 1885-1894 (2010).

Hsiao FY, Huang WF, Wen YW, et al. Thiazolidinediones and cardiovascular events in patients with type 2 diabetes mellitus: a retrospective cohort study of over 473,000 patients using the National Health Insurance database in Taiwan. Drug Saf. 32(8), 675-690 (2009). 
Rosen CJ. The rosiglitazone story: lessons from an FDA Advisory Committee meeting. N. Engl. J. Med. 357(9), 844846 (2007).

Lipscombe LL, Gomes T, Le'vesque LE, et al. Thiazolidinediones and cardiovascular outcomes in older patients with diabetes. JAMA. 298(22), 26342643 (2007).

Masoudi FA, Inzucchi SE, Wang Y, et al. Thiazolidinediones, metformin, and outcomes in older patients with diabetes and heart failure: an observational study. Circulation. 111(5), 583-590 (2005).

Desvergne B, Wahli W. Peroxisome proliferator-activated receptors: nuclear control of metabolism. Endocr. Rev. 20(5), 649-688 (1999).

Goldberg R, Kendall D, Deeg M, et al. A comparison of lipid and glycemic effects of pioglitazone and rosiglitazone in patients with type 2 diabetes and dyslipidemia. Diabetes Care. 28(7), 15471554 (2005).

Karagiannis E, Pfützner A, Forst $\mathrm{T}$, et al. The IRIS V study: pioglitazone improves systemic chronic inflammation in patients with type 2 diabetes under daily routine conditions. Diabetes Technol. Ther. 10(3), 206-212 (2008).

Scheen AJ. Outcomes and lessons from the PROactive study. Diabetes Res. Clin. Pract. 98(2), 175-186 (2012).

Nishio K, Sakurai M, Kusuyama $\mathrm{T}$, et al. A randomized comparison of pioglitazone to inhibit restenosis after coronary stenting in patients with type 2 diabetes. Diabetes Care. 29(1), 101-106 (2006).

Giles TD, Miller AB, Elkayam U, Bhattacharya M, Perez A. Pioglitazone and Heart Failure: Results From a Controlled Study in Patients With Type 2 Diabetes Mellitus and Systolic Dysfunction. J. Card. Fail. 14(6), 445-452 (2008).

Mattoo V, Eckland D, Widel M, et al. Metabolic effects of pioglitazone in combination with insulin in patients with type 2 diabetes mellitus whose disease is not adequately controlled with insulin therapy: results of a six-month, randomized, double-blind, prospective, multicenter, parallel-g. Clin. Ther. 27(5), 554-567 (2005).

Aronoff S, Rosenblatt S, Egan JW, et al. Pioglitazone Hydrochloride
Monotherapy Improves Glycemic Control in the Treatment of Patients With Type 2 Diabetes. Diabetes Care. 23(11), 1605-1611 (2000).

Miyazaki Y, Masafumi M, Defronzo RA. Dose-response effect of pioglitazone on insulin sensitivity and insulin secretion in type 2 diabetes. Diabetes Care. 25(3), 517-523 (2002).

Scherbaum WA, Göke B. Metabolic efficacy and safety of once-daily pioglitazone monotherapy in patients with type 2 diabetes: a double-blind, placebo-controlled study. Horm. Metab. Res. 34(10), 589-595 (2002).

PNFP012 available on: http:// www.trialresultscenter.org/study6911PNFP-012.htm (last visit on 4.03.2016)

Truitt KE, Goldberg RB, Rosenstock J, et al. A 26-week, placebo- and pioglitazone-controlled, dose-ranging study of rivoglitazone, a novel thiazolidinedione for the treatment of type 2 diabetes. Curr. Med. Res. Opin. 26(6), 1321-1331 (2010).

Negro R, Dazzi D, Hassan H, Pezzarossa A. Pioglitazone reduces blood pressure in non-dipping diabetic patients. Minerva Endocrinol. 29(1), 11-17 (2004).

Stuart CA, Howell ME, Yin D. Overexpression of GLUT5 in diabetic muscle is reversed by pioglitazone. Diabetes Care. 30(4), 925-931 (2007).

Tooke JE, Elston LM, Gooding KM, et al. The insulin sensitiser pioglitazone does not influence skin micro- circulatory function in patients with type 2 diabetes treated with insulin. Diabetologia. 49, 1064-1070 (2006).

Kawamori R, Matsuhisa M, Kinoshita $\mathrm{J}$, et al. Pioglitazone enhances splanchnic glucose uptake as well as peripheral glucose uptake in non-insulin-dependent diabetes mellitus. AD-4833 Clamp-OGL Study Group. Diabetes Res. Clin. Pract. 41(1), 35-43 (1998).

Saad MF, Greco S, Osei K, et al. Ragaglitazar improves glycemic control and lipid profile in type 2 diabetic subjects: a 12-week, double-blind, placebo-controlled dose-ranging study with an open pioglitazone arm. Diabetes Care. 27(6), 1324-1329 (2004).

Bogacka I, Xie H, Bray GA, Smith SR. Pioglitazone induces mitochondrial biogenesis in human sub-cutaneous adipose tissue in vivo. Diabetes. 54(5), 1392-1399 (2005).

Wallace TM, Levy JC, Matthews DR. An increase in insulin sensitivity and basal beta-cell function in dia- betic subjects treated with pioglitazone in a placebocontrolled randomized study. Diabet Med. 21(6), 568-576 (2004).

Katavetin P, Eiam-Ong $S$, Suwanwalaikorn S. Pioglitazone reduces urinary protein and urinary transforming growth factor-beta excretion in patients with type 2 diabetes and overt nephropathy. J. Med. Assoc. Thai. 89(2), 170-177 (2006).

McMahon GT, Plutzky J, Daher E, et al. Effect of a peroxisome pro-liferatoractivated receptor-gamma agonist on myocardial blood flow in type 2 diabetes. Diabetes Care. 28(5), 1145-1150 (2005).

Goldstein BJ, Rosenstock J, Anzalone D, Tou C, Ohman KP. Effect of tesaglitazar, a dual PPAR alpha/ gamma agonist, on glucose and lipid abnormalities in patients with type 2 diabetes: a 12week dose-ranging trial. Curr. Med. Res. Opin. 22(12), 2575-2590 (2006).

Gastaldelli A, Miyazaki Y, Mahankali A, et al. The effect of pioglitazone on the liver: role of adiponectin. Diabetes Care. 29(10), 2275-2281 (2006).

Gastaldelli A, Casolaro A, Pettiti $M$ et al. Effect of pio- glitazone on the metabolic and hormonal response to a mixed meal in type II diabetes. Clin. Pharmacol. Ther. 81(2), 205-212 (2007).

Martens FM, Visseren FL, de Koning EJ, Rabelink TJ. Short-term pioglitazone treatment improves vascular function irrespective of metabolic changes in patients with type 2 diabetes. J. Cardiovasc. Pharmacol. 46, 773-778 (2005).

Rosenstock J, Einhorn D, Hershon K, et al. Efficacy and safety of pioglitazone in type 2 diabetes: a randomised, placebocontrolled study in patients receiving stable insulin therapy. Int. J. Clin. Pract. 56, 251-257 (2002).

Einhorn D, Rendell M, Rosenzweig J, et al. Pioglitazone hydrochlo- ride in combination with metformin in the treatment of type 2 diabetes mellitus: a randomized, placebo- controlled study. The Pioglitazone 027 Study Group. Clin. Ther. 22, 1395-1409 (2000). 
Miyazaki Y, Mahankali A, Matsuda $\mathrm{M}$, et al. Improved glycemic control and enhanced insulin sensitivity in type 2 diabetic subjects treated with pioglitazone. Diabetes Care. 24, 710-719 (2001).

Kipnes MS, Krosnick A, Rendell MS, et al. Pioglitazone hydrochloride in combination with sulfonylurea therapy improves glycemic control in patients with type 2 diabetes mellitus: a randomized, placebo-controlled study. Am. J. Med. 111, 10-17 (2001).

Herz M, Johns D, Reviriego J, et al. A randomized, double-blind, placebocontrolled, clinical trial of the effects of pioglitazone on glycemic control and dyslipidemia in oral antihyperglycemic medication-naive patients with type 2 diabetes mellitus. Clin. Ther. 25(4), 10741095 (2003).

Rosenblatt S, Miskin B, Glazer NB, et al. The impact of pioglitazone on glycemic control and atherogenic dyslipidemia in patients with type 2 diabetes mellitus. Coron. Artery Dis. 12(5), 413-423 (2001).

https://clinicaltrials. gov/ct $2 / \mathrm{show} / \mathrm{study} /$ NCT00151710?term=NCT00151710.

Umpierrez G, Issa M, Vlajnic A. Glimepiride versus pioglitazone combination therapy in subjects with type 2 diabetes inadequately controlled on metformin monotherapy: results of a randomized clinical trial. Curr. Med. Res. Opin. 22(4), 751-759 (2006).

Tan M, Johns D, Gonzalez GG, et al. Effects of pioglitazone and glimepiride on glycemic control and insulin sensitivity in Mexican patients with type 2 diabetes mellitus: a multicenter, randomized, double-blind, parallel-group trial. Clin. Ther. 26(5), 680-693 (2004).

Yamanouchi T, Sakai T, Igarashi K, et al. Comparison of metabolic effects of pioglitazone, metformin, and glimepiride over 1 year in Japanese patients with newly diagnosed type 2 diabetes. Diabet. Med. 22(8), 980-985 (2005).

Mazzone T, Meyer PM, Feinstein SB, et al. Effect of pioglitazone compared with glimepiride on carotid intima-media thickness in type 2 diabetes: a randomized trial. JAMA. 296(21), 2572-2581 (2006).

Perriello G, Pampanelli S, Di PC, Brunetti P. Comparison of glycaemic control over 1 year with pioglitazone or gliclazide in patients with type 2 diabetes. Diabet. Med. 23(3), 246-252 (2006).

Matthews DR, Charbonnel BH, Hanefeld M, Brunetti P, Schernthaner G. Long-term therapy with addition of pioglitazone to metformin compared with the addition of gliclazide to metformin in patients with type 2 diabetes: a randomized, comparative study. Diabetes Metab. Res. Rev. 21(2), 167-174 (2005).

Charbonnel BH, Matthews DR, Schernthaner G, Hanefeld M, Brunetti P. A long-term comparison of pioglitazone and gliclazide in patients with type 2 diabetes mellitus: a randomized, doubleblind, parallel- group comparison trial. Diabet. Med. 22(4), 399-405 (2005).

Watanabe I, Tani S, Anazawa T, Kushiro T, Kanmatsuse K. Effect of pioglitazone on arteriosclerosis in comparison with that of glibenclamide. Diabetes. Res. Clin. Pract. 68(2), 104-110 (2005).

Nakamura T, Matsuda T, Kawagoe Y, et al. Effect of pioglitazone on carotid intima-media thickness and arterial stiffness in type 2 diabetic nephropathy patients. Metabolism. 53(10), 1382-1386 (2004).

Nakamura T, Ushiyama C, Osada S, et al. Pioglitazone reduces urinary podocyte excretion in type 2 diabetes patients with micro- albuminuria. Metabolism. 50(10), 1193-1196 (2001).

Tan MH, Johns D, Strand J, et al. Sustained effects of pioglitazone vs. glibenclamide on insulin sensitivity, glycaemic control, and lipid profiles in patients with type 2 diabetes. Diabet. Med. 21(8), 859-866 (2004).

Jain R, Osei K, Kupfer S, Perez AT, Zhang J. Long-term safety of pioglitazone versus glyburide in patients with recently diagnosed type 2 diabetes mellitus. Pharmacotherapy. 26(10), 1388-1395 (2006).

Giles TD, Elkayam U, Bhattacharya M, Perez A, Miller AB. Comparison of pioglitazone vs glyburide in early heart failure: insights from a randomized controlled study of patients with type 2 diabetes and mild cardiac disease. Congest. Heart Fail. 16(3), 111-117 (2010).

Tolman KG, Freston JW, Kupfer $S$, Perez A. Liver safety in patients with type 2 diabetes treated with pioglitazone: results from a 3-year, randomized, comparator-controlled study in the US. Drug Saf. 32(9), 787-800 (2009).

Ramachandran A, Snehalatha C, Salini J, Vijay V. Use of glimepiride and insulin sensitizers in the treatment of type 2 diabetes - a study in Indians. J. Assoc. Physicians India. 52, 459-463 (2004).

Lawrence JM, Reid J, Taylor GJ, et al. Favorable effects of pioglitazone and metformin com- pared with gliclazide on lipoprotein subfractions in overweight patients with early type 2 diabetes. Diabetes Care. 27, 41-46 (2004).

Al Majali K, Cooper MB, Staels $B$, et al. The effect of sensitisation to insulin with pioglitazone on fasting and postprandial lipid metabolism, lipoprotein modification by lipases, and lipid transfer activities in type 2 diabetic patients. Diabetologia. 49(3), 527-537 (2006).

Agarwal R, Saha C, Battiwala M, et al. A pilot randomized controlled trial of renal protection with pioglitazone in diabetic nephropathy. Kidney Int. 68(1), 285-292 (2005).

Fonseca VA, Theuma P, Mudaliar S, et al. Diabetes treatments have differential effects on nontraditional cardiovascular risk factors. J. Diabetes Complications. 20(1), 14-20 (2006).

Shaenko ZA, Racine MS. Efficacy and safety of metformin and pioglitazone in patients with coronary heart disease and type 2 diabetes mellitus. Int. Endocrinol. J. 2(66), 66-70 (2015).

Pavo I, Jermendy G, Varkonyi TT, et al. Effect of pioglitazone compared with metformin on glycemic control and indicators of insulin sensitivity in recently diagnosed patients with type 2 diabetes. J. Clin. Endocrinol. Metab. 88(4), 16371645 (2003).

Hanefeld M, Brunetti P, Schernthaner GH, Matthews DR, Charbonnel BH. One-year glycemic control with a sulfonylurea plus pioglitazone versus a sulfonylurea plus metformin in patients with type 2 diabetes. Diabetes Care. 27(1), 141-147 (2004).

Schernthaner G, Matthews DR, Charbonnel B , Hanefeld M, Brunetti P. Efficacy and safety of pioglitazone versus metformin in patients with type 2 diabetes mellitus: a double-blind, randomized 
trial. J. Clin. Endocrinol. Metab. 89(2), 6068-6076 (2004).

Sharma PK, Bhansali A, Sialy R, Malhotra S, Pandhi P. Effects of pioglitazone and metformin on plasma adiponectin in newly detected type 2 diabetes mellitus. Clin. Endocrinol. (Oxf). 65(6), 722-728 (2006).

Nagasaka S, Aiso Y, Yoshizawa K, Ishibashi S. Comparison of pioglitazone and metformin efficacy using homeostasis model assessment. Diabet Med. 21(2), 136-141 (2004).

Goldberg RB, Kendall DM, Deeg MA, et al. A comparison of lipid and glycemic effects of pioglitazone and rosiglitazone in patients with type 2 diabetes and dyslipidemia. Diabetes Care. 28(7), 1547-1554 (2005).

Derosa G, Cicero AF, Gaddi A, et al. A comparison of the effects of pioglitazone and rosiglitazone combined with glimepiride on prothrombotic state in type 2 diabetic patients with the metabolic syndrome. Diabetes Res. Clin. Pract. 69(1), 5-13 (2005).

Derosa G, D’Angelo A, Ragonesi PD, et al. Metformin- pioglitazone and metformin-rosiglitazone effects on nonconventional cardiovascular risk factors plasma level in type 2 diabetic patients with metabolic syndrome. J. Clin. Pharm.
Ther. 31(4), 375-383 (2006).

Kendall DM, Rubin CJ, Mohideen P, et al. Improvement of glycemic control, triglycerides, and HDL cholesterol levels with muraglitazar, a dual (alpha/ gamma) peroxisome proliferator-activated receptor activator, in patients with type 2 diabetes inadequately controlled with metformin monotherapy: a double-blind, randomized, pioglitazone-comparative study. Diabetes Care. 29(5), 1016-1023 (2006).

Bays H, McElhattan J, Bryzinski BS. A double-blind, randomised trial of tesaglitazar versus pioglitazone in patients with type 2 diabetes mellitus. Diab. Vasc. Dis. Res. 4(3), 181-193 (2007)

Khan MA, St Peter JV, Xue JL. A prospective, randomized comparison of the metabolic effects of pioglitazone or rosiglitazone in patients with type 2 diabetes who were previously treated with troglitazone. Diabetes Care. 25(4), 708711 (2002).

Aljabri K, Kozak SE, Thompson DM. Addition of pioglitazone or bedtime insulin to maximal doses of sulfonylurea and metformin in type 2 diabetes patients with poor glucose control: a prospective, randomized trial. Am. J. Med. 116(4), 230-235 (2004).

Göke B. Improved glycemic control and lipid profile in a randomized study of pioglitazone compared with acarbose in patients with type 2 diabetes mellitus. Treat. Endocrinol. 1(5), 329-336 (2002).

Shimizu H, Oh IS, Tsuchiya T, et al. Pioglitazone increases circulating adiponectin levels and subsequently reduces TNF-alpha levels in type 2 diabetic patients: a randomized study. Diabet. Med. 23(3), 253-257 (2006).

Rosenstock J, Brazg R, Andryuk PJ, et al. Efficacy and safety of the dipeptidyl peptidase-4 inhibitor sitagliptin added to ongoing pioglitazone therapy in patients with type 2 diabetes: a 24-week, multicenter, randomized, double-blind, placebo-controlled, parallel-group study. Clin. Ther. 28(10), 1556-1568 (2006).

Wang $\mathrm{CH}$, Ting $\mathrm{MK}$, Verma $\mathrm{S}$, et al. Pioglitazone increases the numbers and improves the functional capacity of endothelial progenitor cells in patients with diabetes mellitus. Am. Heart J. 152(6), 1051-1058 (2006).

Jin HM, Pan Y. Renoprotection provided by losartan in combination with pioglitazone is superior to renoprotection provided by losartan alone in patients with type 2 diabetic nephropathy. Kidney Blood Press. Res. 30(4), 203-211 (2007). 